\title{
Increased risk and severity of ERCP-related complications associated with asymptomatic common bile duct stones
}

\section{(1) $\odot \ominus$}

\author{
Authors \\ Shuji Tada ${ }^{1}$ \\ Institutions \\ 1 Department of Gastroenterology, Kumamoto City- \\ Hospital, Kumamoto, Japan \\ 2 Department of Gastroenterology, Kumamoto Chuo \\ Hospital, Kumamoto, Japan \\ 3 Department of Biostatics Center, Medical School, \\ Kurume University, Fukuoka, Japan \\ 4 Department of Gastroenterology, Saiseikai Kumamoto \\ Hospital, Kumamoto, Japan
}

Hirokazu Saito ${ }^{1,2}$, Tatsuyuki Kakuma ${ }^{3}$, Yoshihiro Kadono ${ }^{4}$, Atsushi Urata ${ }^{4}$, Kentaro Kamikawa ${ }^{4}$, Haruo Imamura $^{4}$,

submitted 9.11.2016

accepted after revision $\quad 6.2 .2017$

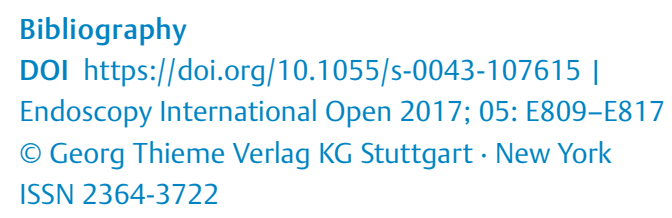

Corresponding author

Hirokazu Saito, Department of Gastroenterology, Kumamoto Chuo Hospital, 1-5-1, Tainoshima, Minami-ku, Kumamoto-City, Kumamoto, 862-0965, Japan

Fax: +81-96-370-4017

arnestwest@yahoo.co.jp

\section{ABSTRACT}

Background and study aims Endoscopic removal of asymptomatic common bile duct stones (CBDS) is generally recommended. Although many reports have described the risk of complications in endoscopic retrograde cholangio- pancreatography (ERCP), no studies have addressed this problem in the context of asymptomatic CBDS. This study examines the risk of complications arising in ERCP for asymptomatic CBDS.

Patients and methods This retrospective study included 425 patients with naive papilla who underwent therapeutic ERCP for choledocholithiasis at 2 institutions in Japan for 2 years. The risk of complications was examined in patients who were divided into the asymptomatic and symptomatic CBDS groups. We used propensity score analysis to adjust for confounding effects.

Results Complications were observed in 32 (7.5\%) of the 425 patients. Of the 358 patients with symptomatic CBDS, 14 patients (3.9\%) had complications. In contrast, of the 67 patients with asymptomatic CBDS, 18 patients (26.9\%) had complications. Propensity score analysis revealed that asymptomatic CBDS was a significant risk factor, with a significantly higher incidence of complications compared with symptomatic CBDS (odds ratio, 5.3). Moderate to severe complications were observed in 15 of 18 patients (83.3\%) in the asymptomatic CBDS group, with significantly more moderate to severe complications than those in the symptomatic CBDS (odds ratio, 6.7).

Conclusions Asymptomatic CBDS carried a high risk of ERCP-related complications, and these were often more severe. In asymptomatic CBDS, endoscopic treatment should be carefully performed after considering the patient's background, and detailed explanation of its possible complications should be given to patients in advance.

\section{Introduction}

Endoscopic retrograde cholangiopancreatography (ERCP) is a useful procedure for diagnosis and treatment of biliopancreatic diseases, and it is the first treatment option for common bile duct stones (CBDS). However, ERCP is technically difficult and has been found to be associated with a high incidence of procedure-related complications, such as pancreatitis, cholangitis, bleeding, and perforation [1-14]. Furthermore, studies have reported that therapeutic ERCP has a higher incidence of com- plications than diagnostic ERCP $[3,5]$ and on occasion can cause fatal complications [2].

Although the natural history of asymptomatic CBDS is unclear, it carries a risk of concurrent cholangitis and pancreatitis. Therefore, treatment is generally recommended in the guidelines of various countries [15, 16], including Japan [17].

However, ERCP for asymptomatic CBDS is a prophylactic measure to prevent complications such as cholangitis and biliary pancreatitis. Because patients are asymptomatic, the risk of ERCP-related complications places a great physical, psychologi- 
cal, and financial burden on the patient that could lead to a lawsuit.

Stones migrating to the common bile duct from the gallbladder often cause CBDS [15]. Prevalence of gallstones increases with age, and the same tendency is observed for CBDS [18]. According to World Population Prospects 2015 published by the United Nations [19], an increase in the elderly population is expected worldwide. Furthermore, diagnostic modalities such as magnetic resonance cholangiopancreatography and endoscopic ultrasound (EUS) have been developed in recent years. Detection of asymptomatic CBDS by chance will increase in the future, and there will probably be more opportunities to consider endoscopic stone removal.

Because ERCP is a high-risk procedure, the indication for $E R C P$, especially in cases of asymptomatic CBDS, should be determined after careful consideration of the risks and benefits of the treatment. However, no reports are available on the risk of ERCP-related complications focusing on asymptomatic CBDS.

This study examined the incidence and severity of complications from ERCP for asymptomatic CBDS in patients with a naive papilla.

\section{Patients and methods}

\section{Study design and patient selection}

We conducted a retrospective study using propensity score analysis at 2 tertiary care centers, Kumamoto City Hospital and Saiseikai Kumamoto Hospital. The study was approved by the Institutional Review Boards of both institutions. Consent was obtained from all patients.

We included patients with CBDS who had naive papilla and normal upper gastrointestinal tract or Billroth I gastrectomy. They underwent therapeutic ERCP in our endoscopic unit between April 2014 and March 2016. Exclusion criteria were prior endoscopic sphincterotomy (EST) or endoscopic papillary balIoon dilation (EPBD), prior to Billroth II or Roux-en-Y reconstruction, patients without EST or EPBD. Finally, 425 patients (67 patients with asymptomatic CBDS and 358 patients with symptomatic CBDS) were included in the study ( $\triangleright$ Fig. 1).

\section{Endoscopists}

ERCP procedures were performed by 15 endoscopists categorized as expert, intermediate, or trainees $(6,3$, and 6 in each group, respectively). When performing the procedure, trainees were assisted by intermediate or expert endoscopists. Endoscopists were considered as expert if they could perform procedures equivalent to Grade 3 of the grading scale for difficulty of ERCP, based on the ERCP core curriculum published in 2016 [20], without assistance; intermediate if they could perform procedures equivalent to Grade 2 without assistance; and trainees if they had performed fewer than 200 ERCP procedures, or could only perform procedures equivalent to Grade 1, with or without assistance.
Total cases with common bile duct stones ( $n=682$ )

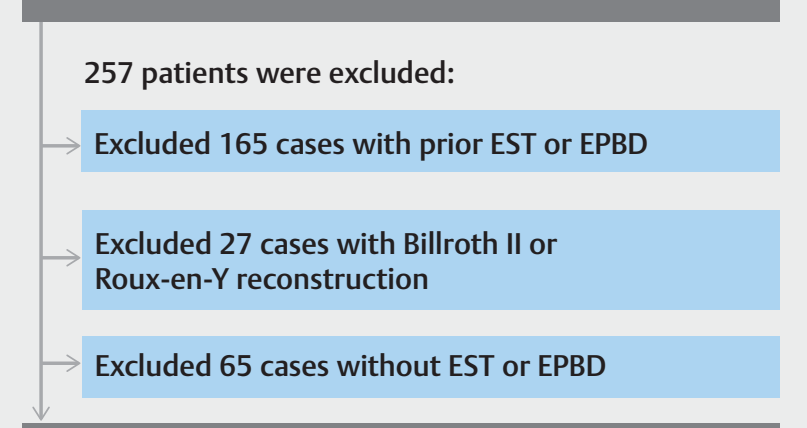

Patients finally included $(n=425)$

EST: endoscopic sphincterotomy

EPBD: endoscopic papillary balloon dilation

- Fig. 1 Flowchart of patient selection.

\section{Scopes and premedication}

Side-viewing duodenoscopes (Olympus JF-260, TJF-260V; Olympus Medical Systems, Tokyo, Japan) were used for all patients. Midazolam and pethidine hydrochloride were injected intravenously for sedation. Scopolamine butylbromide or glucagon was injected intravenously for duodenal relaxation.

\section{Study definitions}

\section{Asymptomatic CBDS and symptomatic CBDS}

Asymptomatic CBDS was defined as CBDS with the absence of symptoms and abnormal blood data associated with CBDS at the time of ERCP. Symptomatic CBDS included cases with cholangitis, obstructive jaundice, biliary pancreatitis, calculus impaction, and elevated liver tests.

\section{Difficult deep cannulation}

Patients who required more than 10 minutes for deep cannulation had a significantly higher risk of post-ERCP pancreatitis (PEP) [21]. We defined cases who required more than 10 minutes for deep cannulation as difficult deep cannulation and used 10 minutes as the cutoff for deep cannulation time.

\section{Complications of ERCP}

Complications of ERCP were defined as any adverse events occurring after the ERCP procedure that required more than 1 night of hospitalization. Complications were defined and graded based on consensus criteria. PEP, hemorrhage, and perforation were defined and graded on the basis of consensus criteria by Cotton et al. [11]. To define and grade cholangitis, we used the Tokyo Guidelines for management of acute cholangitis and cholecystitis published in 2013 (TG2013) [22].

Detailed definitions for complications are shown in $\mathbf{r a b l e ~} \mathbf{1}$, and those for severity of complications are given in $>$ Table 2 . 
- Table 1 Definitions of complications.

\begin{tabular}{|c|c|}
\hline Post-ERCP pancreatitis & $\begin{array}{l}\text { New or worsened abdominal pain combined with serum concentration of amylase that is more than three times the } \\
\text { upper limit of normal at } 24 \mathrm{~h} \text { after ERCP, which required prolongation of the planned admission to at least } 2 \text { days }\end{array}$ \\
\hline Hemorrhage & ERCP-related bleeding with melena, hematemesis, or decrease in hemoglobin concentration \\
\hline Perforation & Presence of air or contrast medium in the retroperitoneal space on abdominal CT \\
\hline Cholangitis & $\begin{array}{l}\text { Definitive diagnosis was reached when } 1 \text { item from the systematic inflammation category, one from cholestasis cate- } \\
\text { gory, and } 1 \text { from imaging category were present. } \\
\text { (1) Systematic inflammation: } \\
\text { 1. Fever }>38^{\circ} \mathrm{C} \text { and/or shivering; } \\
2 \text {. Evidence of inflammatory response based on laboratory data } \\
W B C<4000 / \mu l \text { or }>10000 / \mu l \text { and } C R P \geq 1 \mathrm{mg} / \mathrm{dL} \\
\text { (2) Cholestasis: } \\
1 \text {. Jaundice } \\
\text { T-bil } \geq 2 \mathrm{mg} / \mathrm{dL} \\
2 . \text { Abnormal liver function test } \\
\text { ALP (IU) }>1.5 \times \text { standard, } \mathrm{Y} \text { - GT (IU) }>1.5 \times \text { standard, AST (IU) }>1.5 \times \text { standard and ALT (IU) }>1.5 \times \text { standard } \\
\text { (3) Imaging: } \\
\text { 1. Biliary dilatation } \\
\text { 2. Evidence of the etiology on imaging }\end{array}$ \\
\hline
\end{tabular}

ERCP, endoscopic retrograde cholangiopancreatography; CT, computed tomography; WBC, white blood cell; CRP, C-reactive protein; T-bil, total bilirubin; ALP, alkaline phosphatase; $\gamma$-GT, $\gamma$-glutamyltransferase; AST, aspartate aminotransferase; ALT, alanine aminotransferase; Standard: upper limit of normal value

- Table 2 Definitions of severity of complications.

\begin{tabular}{|c|c|c|c|}
\hline & Mild & Moderate & Severe \\
\hline Post-ERCP pancreatitis & $\begin{array}{l}\text { Pancreatitis that required } \\
\text { prolongation of the planned } \\
\text { hospitalization for } 2-3 \text { days }\end{array}$ & $\begin{array}{l}\text { Pancreatitis that required hospitaliza- } \\
\text { tion for } 4 \text { - } 10 \text { days }\end{array}$ & $\begin{array}{l}\text { Pancreatitis that required hospitalization } \\
\text { for }>10 \text { days, necessitated percutaneous } \\
\text { drainage or surgery }\end{array}$ \\
\hline Hemorrhage & $\begin{array}{l}\text { Hemoglobin level dropped to } \\
<3 \mathrm{~g} / \mathrm{dL} \text {, with no need for a } \\
\text { blood transfusion }\end{array}$ & $\begin{array}{l}\text { Blood transfusion: up to } 4 \text { units of } \\
\text { blood were needed }\end{array}$ & $\begin{array}{l}\text { Blood transfusion of up to } \geq 5 \text { units, sur- } \\
\text { gery or angiography }\end{array}$ \\
\hline Perforation & $\begin{array}{l}\text { Only very slight leak of fluid or } \\
\text { contrast medium and treatable } \\
\text { for } \leq 3 \text { days }\end{array}$ & $\begin{array}{l}\text { Perforation treated medically for } \\
4-10 \text { days }\end{array}$ & $\begin{array}{l}\text { Perforation treated medically for } \\
>10 \text { days or necessitated percutaneous } \\
\text { drainage or surgery }\end{array}$ \\
\hline Cholangitis & $\begin{array}{l}\text { Mild acute cholangitis does not } \\
\text { meet the criteria of severe or } \\
\text { moderate acute cholangitis }\end{array}$ & $\begin{array}{l}\text { Cholangitis that meets any } 2 \text { of the } \\
\text { following criteria: } \\
\text { 1. Abnormal WBC count: } \\
>12,000 / \mathrm{mm}^{3} \text { or }<4,000 / \mathrm{mm}^{3} \\
\text { 2. High fever: } \geq 39^{\circ} \mathrm{C} \\
\text { 3. Age: } \geq 75 \text { years } \\
\text { 4. Hyperbilirubinemia: total bilirubin } \\
\geq 5 \mathrm{mg} / \mathrm{dL} \\
\text { 5. Hypoalbuminemia: }<\text { standard } \times \\
0.7 \mathrm{~g} / \mathrm{dL}\end{array}$ & $\begin{array}{l}\text { Cholangitis that meets at least } 1 \text { of any of } \\
\text { the following criteria: } \\
\text { 1. Cardiovascular dysfunction: } \\
\text { Hypotension requiring dopamine } \\
\geq 5 \mu \mathrm{g} / \mathrm{kg} / \mathrm{min} \text { or any dose of norepi- } \\
\text { nephrine } \\
\text { 2. Neurological dysfunction: } \\
\text { Disturbance of consciousness } \\
\text { 3. Respiratory dysfunction: } \\
\text { PaO2/FiO2 ratio }<300 \\
\text { 4. Renal dysfunction: Oliguria or serum } \\
\text { creatinine }>2.0 \mathrm{mg} / \mathrm{dL} \\
\text { 5. Hepatic dysfunction: } \\
\text { PT-INR }>1.5 \\
\text { 6. Hematological dysfunction: } \\
\text { Platelet count }<100,000 / \mathrm{mm}^{3}\end{array}$ \\
\hline
\end{tabular}

WBC, white blood cell; standard, upper limit of normal value 


\section{Outcome}

The primary outcome was incidence of ERCP-related complications in patients with asymptomatic CBDS. The secondary outcome was the severity of ERCP-related complications in these patients.

\section{Statistical analysis}

Associations between complications (with/without) and risk factors were assessed using chi-square and Fisher's exact tests for univariate analysis as well as logistic regression for multivariable analysis. Risk factors with $P$ values less than 0.1 in the univariate analysis were used in the multivariable analysis. Similar univariate analysis was performed to examine associations between symptom status (asymptomatic/symptomatic) and risk factors.

Risk factors that were associated with both complications (with/without) and symptom status (asymptomatic/symptomatic) in univariate analysis were considered to be potential confounders (shown as confounding factor group A). In addition, risk factors known to be confounders in previous reports were identified as additional potential confounders (shown as confounding factor group B). Before testing an effect of symptom status on complications, we converted these two sets of confounding factors into propensity scores based on logistic regression, and an adjusted odds ratio was obtained to represent the effects of symptoms on complications.

A $P$ value $<0.05$ was considered as indicating statistical significance. All statistical analyses were performed with JMP ${ }^{\circledR}$ Pro 12 (SAS Institute, Cary, NC, USA).

\section{Results}

\section{Indications for ERCP}

The indications for ERCP were asymptomatic CBDS in $67 \mathrm{pa}$ tients (15.8\%), cholangitis in 203 (47.8\%), obstructive jaundice by CBDS in 41 (9.6\%), biliary pancreatitis in 54 (12.7\%), calculus impaction in $14(3.3 \%)$, and elevated liver tests without jaundice in $46(10.8 \%)$.

\section{Patient demographics and characteristics in symptomatic and asymptomatic CBDS group}

The participants of this study were 425 patients (201 women and 224 men), with the mean age of $74.6 \pm 14.0$ years. Details of patient demographics and characteristics in symptomatic and asymptomatic CBDS patients are described in - Table 3. Endoscopic large balloon dilation (EPLBD) included EPBD because only two patients (one with symptomatic CBDS and the other with asymptomatic CBDS) underwent EPLBD. Regarding devices used for stone removal, the 82 cases that underwent single-stage stone removal with EST or EPBD were shown.

Four factors were significant in univariate analysis: serum bilirubin, antibiotics, deep cannulation time, and biliary stent placement. Other factors were not significant.

\section{Modality for diagnosis of asymptomatic CBDS}

Asymptomatic CBDS was diagnosed using imaging (ultrasound [US] and/or EUS and/or computed tomography (CT) and/or magnetic resonance imaging $[\mathrm{MRI}]$ ) or dilated common bile duct. Of 67 asymptomatic CBDS, 65 were diagnosed on the basis of the presence of CBDS using imaging: 6 cases were found using US, 1 case using EUS, 21 cases using CT, 14 cases using MRI, and 23 cases using more than 2 modalities. Two cases were diagnosed on the basis of dilated bile duct.

\section{ERCP procedures}

All patients received therapeutic ERCP for CBDS. Of the 425 patients, 413 (97.2\%) underwent successful deep cannulation. Of 358 patients with symptomatic CBDS, 10 (2.8\%) did not undergo successful deep cannulation. Of 67 patients with asymptomatic CBDS, 2 (3.0\%) did not undergo successful deep cannulation. EST was performed in 345 patients (81.2\%), EPBD in 41 (9.6\%) (EPBD without EST in 39 and EPLBD with EST in 2), and precut sphincterotomy in 27 (6.4\%). Pancreatic stents were placed significantly more in cases of difficult deep cannulation (rates of pancreatic stent placement: deep cannulation time, $\leq 10$ minutes, 23/275(8.4\%) vs. deep cannulation time, $>10$ minutes, $43 / 150$ (28.7\%); $P<0.0001)$.

\section{Percentage of CBDS actually found}

Of 67 asymptomatic CBDS diagnosed before performing ERCP, $56(83.6 \%)$ were actually detected using ERCP.

\section{Incidence rates and severity of ERCP-related complications}

Of 425 patients, $32(7.5 \%)$ suffered a complication, including pancreatitis in 19 patients (4.5\%), cholangitis in 5 (1.2\%), perforation in $2(0.47 \%)$, and hemorrhage in $6(1.4 \%)$. Complications were mild in 11 cases (34.4\%) and moderate or severe in 21 cases $(65.6 \%)$. All patients with ERCP-related complications were treated successfully without surgery. Of 358 patients with symptomatic CBDS, 14 (3.3\%) had complications, whereas 18 of 67 patients with asymptomatic CBDS (26.9\%) had complications. Univariate analyses showed that the rate of complications was significantly higher in patients with asymptomatic CBDS than in patients with symptomatic CBDS (26.9\%, 18 of 67 , vs. $3.9 \%, 14$ of 358 ; odds ratio, 9.0; $95 \%$ confidence interval (Cl), 4.2-19.3; $P<0.0001$ ) ( $\triangleright$ Table 4). Of 18 ERCP-related complications in patients with asymptomatic CBDS, 3 were mild and 15 were moderate or severe. Of 14 ERCP-related complications in patients with symptomatic CBDS, 8 were mild and 6 were moderate or severe. Moderate or severe complications were significantly more frequent in patients with asymptomatic CBDS than in patients with symptomatic CBDS (83.3\%, 15 of 18 , vs. $42.9 \%$, 6 of 14 ; odds ratio, $6.7 ; 95 \% \mathrm{Cl}, 1.3-34.0 ; P=$ 0.027) ( $\triangleright$ Table 5).

\section{Types of ERCP-related complications}

PEP was the most frequent complication. PEP occurred more often in patients with asymptomatic CBDS than in patients with symptomatic CBDS $(16.4 \%, 11$ of 67 , vs. $2.2 \%, 8$ of 358 ; 
- Table 3 Patient demographics and characteristics in symptomatic and asymptomatic CBDS patients.

\begin{tabular}{|c|c|c|c|}
\hline & Symptomatic CBDS & Asymptomatic CBDS & $P$ value \\
\hline Age ( $<75$ years $/ \geq 75$ years $)$ & $142(33.4 \%) / 216(50.8 \%)$ & $33(7.8 \%) / 34(8.0 \%)$ & 0.18 \\
\hline $\operatorname{Sex}(M / F)$ & $187(44.0 \%) / 171(40.2 \%)$ & $37(8.7 \%) / 30(7.1 \%)$ & 0.69 \\
\hline Endoscopist (Expert/Intermediate/Trainee) & $184(43.3 \%) / 80(18.8 \%) / 94(22.1 \%)$ & $32(7.5 \%) / 16(3.8 \%) / 19(4.5 \%)$ & 0.86 \\
\hline Coexisting illness (Yes/No) & $175(41.2 \%) / 183(43.1 \%)$ & $29(6.8 \%) / 38(8.9 \%)$ & 0.43 \\
\hline Abdominal surgical history (No surgery/Billroth I) & $349(82.1 \%) / 9(2.1 \%)$ & $65(15.3 \%) / 2(0.47 \%)$ & 0.69 \\
\hline Serum bilirubin (Normal/ Elevated) & $98(23.1 \%) / 260(61.2 \%)$ & $57(13.4 \%) /$ & $<0.0001$ \\
\hline Platelet count $\left(<10^{4} \mid \geq 10^{4}\right)$ & $31(7.3 \%) / 327(76.9 \%)$ & $6(1.4 \%) / 61(14.4 \%)$ & 1.0 \\
\hline Prothrombin time $(\leq 1.5 />1.5)$ & $291(75.2 \%) / 33(8.5 \%)$ & $61(15.8 \%) / 2(0.52 \%)$ & 0.092 \\
\hline Antithrombotic drug (Yes/No) & $93(21.9 \%) / 265(62.4 \%)$ & $11(2.6 \%) / 56(13.2 \%)$ & 0.12 \\
\hline $\begin{array}{l}\text { Chemoprevention (Yes [rectal indomethacin/ } \\
\text { Protease inhibitor]/No) }\end{array}$ & $\begin{array}{l}94(22.1 \%)[4(0.94 \%) / 90(21.2 \%)] / \\
264(62.1 \%)\end{array}$ & $\begin{array}{l}10(2.4 \%)[2(0.47 \%) / 8(1.9 \%)] / \\
57(13.4 \%)\end{array}$ & 0.062 \\
\hline Antibiotics (Yes/No) & $298(70.1 \%) / 60(14.1 \%)$ & $19(4.5 \%) / 48(11.3 \%)$ & $<0.0001$ \\
\hline Periampullary diverticulum (Yes/No) & $83(19.5 \%) / 275(64.7 \%)$ & $20(4.7 \%) / 47(11.1 \%)$ & 0.28 \\
\hline Deep cannulation time ( $\leq 10 \mathrm{~min} />10 \mathrm{~min})$ & $241(56.7 \%) / 117(27.5 \%)$ & $34(8.0 \%) / 33(7.8 \%)$ & 0.012 \\
\hline $\begin{array}{l}\text { Sphincterotomy technique (Precut sphincterotomy/ } \\
\text { Others [EST/EPBD/unsuccessful deep cannulation)]) }\end{array}$ & $\begin{array}{l}16(3.8 \%) / 342(80.5 \%)[293(68.9 \%) / \\
39(9.2 \%) / 10(2.4 \%)]\end{array}$ & $\begin{array}{l}7(1.7 \%) / 60(14.1 \%)[56(13.2 \%) / \\
2(0.47 \%) / 2(0.47 \%)]\end{array}$ & 0.070 \\
\hline $\begin{array}{l}\text { Devices used for stone removal (balloon/basket/ } \\
\text { lithotripter) }\end{array}$ & $33(40.2 \%) / 17(20.7 \%) / 4(4.9 \%)$ & $15(18.3 \%) / 11(13.4 \%) / 2(2.5 \%)$ & 0.78 \\
\hline Biliary stent placement (Yes/No) & $312(73.4 \%) / 46(10.8 \%)$ & $35(8.2 \%) / 32(7.5 \%)$ & $<0.0001$ \\
\hline Contrast injections into pancreatic duct (Yes/No) & $193(45.4 \%) / 165(38.8 \%)$ & $42(9.9 \%) / 25(5.9 \%)$ & 0.23 \\
\hline Pancreatic stent placement (Yes/No) & $53(12.5 \%) / 305(71.8 \%)$ & $13(3.1 \%) / 54(12.7 \%)$ & 0.36 \\
\hline Stone number $(\leq 1 / \geq 2)$ & $241(56.7 \%) / 117(27.5 \%)$ & $47(11.1 \%) / 20(4.7 \%)$ & 0.78 \\
\hline Stone size $(<10 \mathrm{~mm} / \geq 10 \mathrm{~mm})$ & $272(64.0 \%) / 86(20.2 \%)$ & $48(11.3 \%) / 19(4.5 \%)$ & 0.44 \\
\hline Diameter of common bile duct $(<10 \mathrm{~mm} / \geq 10 \mathrm{~mm})$ & $141(33.2 \%) / 217(51.1 \%)$ & $31(7.3 \%) / 36(8.5 \%)$ & 0.34 \\
\hline
\end{tabular}

CBDS, common bile duct stones, EST: endoscopic sphincterotomy, EPBD: endoscopic papillary balloon dilation

- Table 4 Frequency of complications in symptomatic and asymptomatic CBDS patients.

\begin{tabular}{|l|l|l|l|l|}
\hline CBDS & With complications & Without complications & $\boldsymbol{P}$ value & Odds ratio \\
\hline Symptomatic & $14(3.9 \%)$ & $344(96.1 \%)$ & \\
\hline Asymptomatic & $18(26.9 \%)$ & $49(73.1 \%)$ & $p<0.0001$ & 9.0 \\
\hline CBDS, common bile duct stones; Cl confidence interval & & \\
\hline
\end{tabular}

- Table 5 Severity of complications in symptomatic and asymptomatic CBDS patients.

\begin{tabular}{|l|c|c|c|c|}
\hline Severity & Symptomatic CBDS & Asymptomatic CBDS & P value & Odds ratio \\
\hline Mild & $8(57.1 \%)$ & $3(16.7 \%)$ & & $95 \%$ Cl \\
\hline Moderate to severe & $6(42.9 \%)$ & $15(83.3 \%)$ & 0.027 & 6.7 \\
\hline CBDS, common bile duct stones; Cl confidence interval & & $1.3-34.0$ \\
\hline
\end{tabular}


- Table 6 Types of complications in symptomatic and asymptomatic CBDS patients.

\begin{tabular}{|l|l|l|l|}
\hline Complications & Symptomatic CBDS & Asymptomatic CBDS & P value \\
\hline Post-ERCP pancreatitis & $8 / 358(2.2 \%)$ & $11 / 67(16.4 \%)$ & $<0.0001$ \\
\hline Cholangitis & $2 / 358(0.56 \%)$ & $3 / 67(4.5 \%)$ & 0.030 \\
\hline Perforation & $0 / 358(0 \%)$ & $2 / 67(3.0 \%)$ & 0.025 \\
\hline Hemorrhage & $4 / 358(1.1 \%)$ & $2 / 67(3.0 \%)$ & 0.24 \\
\hline CBDS, common bile duct stones & & & \\
\hline
\end{tabular}

$P<0.0001)$. Moderate or severe pancreatitis occurred in 9 of 11 patients with asymptomatic CBDS (81.8\%). Other complications, such as cholangitis, perforation, and hemorrhage, occurred in a small number of cases. Cholangitis and perforation occurred more often in patients with asymptomatic CBDS than in patients with symptomatic CBDS: cholangitis, $4.5 \%, 3$ of 67 , vs. $0.56 \%, 2$ of $358 ; P=0.030$; perforation, $3.0 \%, 2$ of 67 , vs. $0 \%$, 0 of $358 ; P=0.025$. The incidence of hemorrhage was not significantly different between patients with asymptomatic CBDS and patients with symptomatic CBDS (1.1\%, 4 of 358 , vs. $3.0 \%, 2$ of 67; $P=0.24)(>$ Table 6$)$.

\section{Risk factors for ERCP-related complications}

Results of univariate and multivariable analyses of risk factors for complications are presented in $>$ Table 7 and $>$ Table 8. Seven factors were significant in univariate analysis: indication for ERCP (asymptomatic CBDS), deep cannulation time (>10 min), sphincter technique (precut sphincterotomy), serum bilirubin (normal), biliary stent placement (No), pancreatic stent placement (Yes), and antibiotics (No). However, in multivariable analysis, the only indication for ERCP (asymptomatic CBDS) was the presence of significant risk factors.

\section{Results of propensity score analysis}

CBDS status was significantly associated with ERCP-related complications after adjustment for confounding factors. Specifically, odds for complications were 5.3 times higher in patients with asymptomatic CBDS than in patients with symptomatic CBDS ( $\triangleright$ Table 9 ).

\section{Discussion}

The aim of the current study was to examine incidence and severity of complications from ERCP for asymptomatic CBDS. Because this was a retrospective study, confounding factors were adjusted by propensity scores. The results showed that asymptomatic CBDS was the most significant factor associated with ERCP-related complications, and that the rates of moderate to severe complications were significantly higher in patients with asymptomatic CBDS than in patients with symptomatic CBDS.

A previous study showed that ERCP complications were mostly associated with therapeutic ERCP [3]. In a prospective cohort study, the incidence of complications of therapeutic ERCP was $9.8 \%$, with a $5.4 \%$ incidence of pancreatitis [2]. Several reports describe the overall incidence rates of complica- tions in patients with CBDS. However, there are no published data regarding risk of complications from ERCP for asymptomatic CBDS. In the current study, overall incidence of complications from ERCP for CBDS was $7.5 \%$, which is comparable to rates found in earlier studies $[2,8]$.

The most common complication of ERCP for asymptomatic CBDS was PEP. Although the mechanism of PEP has not been clearly elucidated, it is thought to involve congestion of pancreatic juice caused by edema of the papilla associated with cannulation, as well as conversion of trypsinogen to trypsin in pancreatic acinar cells and activation of neutrophils [23].

In the asymptomatic CBDS group, the rate of difficult deep cannulation was significantly higher than in the symptomatic CBDS group. Small papillary orifice is a factor related to difficult biliary cannulation [24]. In asymptomatic CBDS, small papillary orifice might be more than symptomatic CBDS because of low bile duct pressure owing to the absence of cholestasis compared with symptomatic CBDS. This may be a reason for the increased difficult deep cannulation rate in the asymptomatic group. Because of the increase in difficult deep cannulation in asymptomatic CBDS, edema of the papilla associated with cannulation, leading to the blockage of pancreatic juice flow, and its subsequent activation of trypsin and neutrophils may more likely occur in asymptomatic CBDS.

Although cholangitis and perforation were significantly more common in patients with asymptomatic CBDS than in patients with symptomatic CBDS, the analysis of the results is problematic since there were few patients suffering from these complications. Cholangitis was more common in patients with asymptomatic CBDS; this might be related to the fact that many patients were not administered prophylactic antimicrobials.

In an earlier report, complications associated with EST were mild in approximately $40 \%$ of patients and moderate to severe in $60 \%$ of patients [2]. We observed moderate to severe complications in 21 of 32 patients (65.6\%). Moderate to severe complications occurred in 6 of 14 patients with symptomatic CBDS (42.9\%) and in 15 of 18 patients with asymptomatic CBDS (83.3\%). The authors suggested that ERCP for asymptomatic CBDS is associated with a higher incidence of complications, with more moderate to severe complications than in symptomatic CBDS.

Prevalence of CBDS varies according to report, and prevalence of CBDS in patients with symptomatic gallstones was reported to be $3.4 \%$ to $27 \%[18,25-27]$. The natural history of 
- Table 7 Results of univariable analysis of risk factors for complications.

\begin{tabular}{|c|c|c|c|}
\hline Significant in univariable analysis & With complications & Without complications & $P$ value \\
\hline Indication of ERCP & & & $<0.0001$ \\
\hline " Symptomatic CBDS & $14(3.3 \%)$ & $344(80.9 \%)$ & \\
\hline - Asymptomatic CBDS & $18(4.2 \%)$ & $49(11.5 \%)$ & \\
\hline Deep cannulation time & & & 0.001 \\
\hline . $\leq 10 \min$ & $12(2.8 \%)$ & $263(61.9 \%)$ & \\
\hline " >10 min & $20(4.7 \%)$ & $130(30.6 \%)$ & \\
\hline Sphincterotomy technique & & & 0.022 \\
\hline - Precut sphincterotomy & $5(1.2 \%)$ & $18(4.2 \%)$ & \\
\hline - Others & $27(6.4 \%)$ & $375(88.2 \%)$ & \\
\hline Serum bilirubin & & & 0.0002 \\
\hline - Normal & $22(5.2 \%)$ & $133(31.3 \%)$ & \\
\hline " Elevated & $10(2.4 \%)$ & $260(61.2 \%)$ & \\
\hline Biliary stent placement & & & 0.0005 \\
\hline - Yes & $18(4.2 \%)$ & $329(77.4 \%)$ & \\
\hline - No & $14(3.3 \%)$ & $64(15.1 \%)$ & \\
\hline Pancreatic stent placement & & & 0.019 \\
\hline - Yes & $10(2.4 \%)$ & $56(13.2 \%)$ & \\
\hline - No & $22(5.2 \%)$ & $337(79.3 \%)$ & \\
\hline Antibiotics & & & 0.002 \\
\hline - Yes & $16(3.8 \%)$ & $301(70.8 \%)$ & \\
\hline - No & $16(3.8 \%)$ & $92(21.7 \%)$ & \\
\hline \multicolumn{4}{|l|}{ Not significant } \\
\hline Age ( $<75$ years $/ \geq 75$ years) & $12(2.8 \%) / 20(4.7 \%)$ & $163(38.4 \%) / 230(54.1 \%)$ & 0.71 \\
\hline $\operatorname{Sex}(M / F)$ & $15(3.5 \%) / 17(4.0 \%)$ & $209(49.2 \%) / 184(43.3 \%)$ & 0.58 \\
\hline Endoscopist (Expert/Intermediate/Trainee) & $14(3.3 \%) / 7(1.7 \%) / 11(2.6 \%)$ & $202(47.5 \%) / 89(20.9 \%) / 102(24.0 \%)$ & 0.57 \\
\hline Coexisting illness (Yes/No) & $12(2.8 \%) / 20(4.7 \%)$ & $192(45.2 \%) / 201(47.3 \%)$ & 0.27 \\
\hline Abdominal surgical history (No surgery/Billroth I) & $32(7.5 \%) / 0(0 \%)$ & $382(89.9 \%) / 11(2.6 \%)$ & 1.0 \\
\hline Platelet count $\left(<10^{4} \mid \geq 10^{4}\right)$ & $5(1.2 \%) / 27(6.4 \%)$ & $32(7.5 \%) / 361(84.9 \%)$ & 0.18 \\
\hline Prothrombin time $(\leq 1.5 />1.5)$ & $28(7.2 \%) / 1(0.26 \%)$ & $324(83.7 \%) / 34(8.8 \%)$ & 0.50 \\
\hline Antithrombotic drug (Yes/No) & $7(1.7 \%) / 25(5.9 \%)$ & $97(22.8 \%) / 296(69.7 \%)$ & 0.83 \\
\hline Chemoprevention (Yes/No) & $5(1.2 \%) / 27(6.4 \%)$ & $99(23.3 \%) / 294(69.2 \%)$ & 0.29 \\
\hline Periampullary diverticulum (Yes/No) & $5(1.2 \%) / 27(6.4 \%)$ & $98(23.1 \%) / 295(69.4 \%)$ & 0.29 \\
\hline Contrast injections into pancreatic duct (Yes/No) & $22(5.2 \%) / 10(2.4 \%)$ & $213(50.1 \%) / 180(42.4 \%)$ & 0.14 \\
\hline Stone number $(\leq 1 / \geq 2)$ & $25(5.9 \%) / 7(1.7 \%)$ & $263(61.9 \%) / 130$ (30.6\%) & 0.24 \\
\hline Stone size $(<10 \mathrm{~mm} / \geq 10 \mathrm{~mm})$ & $25(5.9 \%) / 7(1.7 \%)$ & $295(69.4 \%) / 98(23.1 \%)$ & 0.83 \\
\hline Diameter of common bile duct (<10 mm/ $\geq 10 \mathrm{~mm})$ & $15(3.5 \%) / 17(4.0 \%)$ & $157(36.9 \%) / 236(55.5 \%)$ & 0.46 \\
\hline
\end{tabular}


D Table 8 Results of the multivariable analysis of risk factors for complications.

\begin{tabular}{|l|l|l|}
\hline & Odds ratio & $\mathbf{9 5 \%} \mathbf{C l}$ \\
\hline Indication of ERCP (Asymptomatic CBDS) & 4.0 & $1.4-11.8$ \\
\hline Deep cannulation time (> 10 min) & 2.0 & 0.008 \\
\hline Sphincterotomy technique (Precut sphincterotomy) & 1.9 & $0.48-6.9$ \\
\hline Serum bilirubin (Normal) & 1.8 & 0.11 \\
\hline Biliary stent placement (No) & 2.1 & 0.35 \\
\hline Pancreatic stent placement (Yes) & 2.0 & $0.83-5.1$ \\
\hline Antibiotics (No) & 1.2 & $0.73-5.2$ \\
\hline CBDS, common bile duct stones; Cl confidence interval & & 0.1 \\
\hline
\end{tabular}

- Table 9 Effect of symptom status adjusted for confounding factors.

\begin{tabular}{|c|c|c|}
\hline & Likelihood ratio $\mathrm{X} 2 /$ (Odds ratio) & $P$ value $/(95 \% \mathrm{Cl})$ \\
\hline Symptom status (Asymptomatic CBDS/Symptomatic CBDS) & $12.3 /(5.3)$ & $0.0004 /(2.1-14.2)$ \\
\hline Propensity score group $\mathrm{A}^{1}$ & 6.8 & 0.078 \\
\hline Propensity score group $\mathrm{B}^{2}$ & 3.4 & 0.33 \\
\hline \multicolumn{3}{|c|}{$\begin{array}{l}\text { CBDS, common bile duct stones; CI, confidence interval } \\
1 \text { a Propensity score group A: Risk factors that were associated with both complications (with/without) and symptom status (symptomatic/asymptomatic) in uni- } \\
\text { variable analysis: Deep cannulation time, sphincterotomy technique, serum bilirubin, biliary stent placement and antibiotics were included. } \\
2 \text { b Propensity score group B: Risk factors that were known as confounders in the literature: Age, sex, endoscopist, coexisting illness, antithrombotic drug, chemo- } \\
\text { prevention, contrast injections into pancreatic duct, pancreatic stent placement and diameter of common bile duct were included. }\end{array}$} \\
\hline
\end{tabular}

CBDS is not well known, but it was reported that in one-third of patients with CBDS the stones passed spontaneously within 6 weeks of laparoscopic cholecystectomy [25]. However, CBDS can result in complications such as pain, cholangitis, and pancreatitis, which are often serious. A study in which patients with gallstones underwent follow-up observation for 10 years described that approximately one-fourth of patients had CBDS-related events, such as pain, jaundice, and cholangitis [18]. Therefore, whenever CBDS is detected, even when asymptomatic, endoscopic treatment is recommended in the guidelines of various countries $[15,16]$, including Japan [17].

Laparoscopic CBD exploration (LCBDE) is another option for treatment for CBDS. Previous studies showed that $L C B D E$ is as safe and effective as endoscopic stone removal, with nearly the same rates of complications [28]. However, LCBDE has not been widely used given the lack of equipment and advanced skills required to perform the procedure $[16,29]$. Furthermore, surgical management is more invasive than endoscopic treatment in patients with CBDS, particularly asymptomatic CBDS. Therefore, the use of LCBDE is limited to cases of unavailability or failure of ERCP [29]. It would be difficult to accept LCBDE as an alternative to ERCP in asymptomatic CBDS.

We found a high risk of complications arising from ERCP for asymptomatic CBDS, with more moderate to severe complications in this group of patients. Complications have been reported to be more severe in elderly patients undergoing endoscopic stone removal [30]. Asymptomatic CBDS should be carefully treated by ERCP after considering the patient's background, particularly for elderly patients. As evidence-based clinical practice guidelines for cholelithiasis 2016 [17] have mentioned, in asymptomatic CBDS, follow-up observation may be done for some patients with advanced age, poor activities of daily living, or serious coexisting illness.

The current study has several limitations. First, although the propensity score analysis was used to adjust for potential confounding effects, some unmeasured residual confounding effects may not have been excluded in our analyses. Second, the sizes of the samples obtained from the 2 institutions were different: 102 patients from Kumamoto City Hospital and 323 patients from Saiseikai Kumamoto Hospital. Still, visual inspection indicated that the data from both institutions seemed to be similar in key risk factors for complications.

\section{Conclusion}

In conclusion, we examined incidence rates and severity of complications of ERCP for asymptomatic CBDS by propensity score analysis. We found that asymptomatic CBDS was a significant risk factor for ERCP-related complications. In patients with asymptomatic CBDS, the rates of complications were significantly higher, and there were significantly more moderate to severe complications compared with patients with symptomatic CBDS. When performing ERCP for asymptomatic CBDS, endoscopists should thoroughly explain in advance its possible 
complications to patients. In asymptomatic CBDS, particularly for elderly patients, endoscopic treatment should be carefully performed after considering the patient's background.

\section{Acknowledgements}

We thank the staff at both participating institutions for helpful advice on planning of the present study. The advisers included Drs. Takehiko Koga, Hisashi Itoshima, Masafumi Sakaguchi, Kimitaka Shioya, Kouichi Kudo, and Hideto Chikazawa from Saiseikai Kumamoto Hospital and Drs. Tomoyuki Goto, Kazuki Inamura, Norihito Iwasaki, and Satoshi Yamabe from Kumamoto City Hospital.

\section{Competing interests}

None

\section{References}

[1] Anderson MA, Fisher L, Jain R et al. Complications of ERCP. Gastrointest Endosc 2012; 75: 467-473

[2] Freeman ML, Nelson DB, Sherman S et al. Complications of endoscopic biliary sphincterotomy. N Engl J Med 1996; 335: 909-918

[3] Masci E, Toti G, Mariani A et al. Complications of diagnostic and therapeutic ERCP: a prospective multicenter study. Am J Gastroenterol 2001; 96: 417-423

[4] Freeman ML, DiSario JA, Nelson DB et al. Risk factors for post-ERCP pancreatitis: a prospective, multicenter study. Gastrointest Endosc 2001; 54: $425-434$

[5] Loperfido S, Angelini G, Benedetti G et al. Major early complications from diagnostic and therapeutic ERCP: a prospective multicenter study. Gastrointest Endosc 1998; 48: 1- 10

[6] Vandervoort ], Soetikno RM, Tham TC et al. Risk factors for complications after performance of ERCP. Gastrointest Endosc 2002; 56: 652 656

[7] Christensen M, Matzen P, Schulze S et al. Complications of ERCP: a prospective study. Gastrointest Endosc 2004; 60: 721 - 731

[8] Rabenstein T, Schneider HT, Bulling D et al. Analysis of the risk factors associated with endoscopic sphincterotomy techniques: preliminary results of a prospective study, with emphasis on the reduced risk of acute pancreatitis with low-dose anticoagulation treatment. Endoscopy 2000; 32: $10-19$

[9] Williams EJ, Taylor S, Fairclough P et al. Risk factors for complication following ERCP; results of a large-scale, prospective multicenter study. Endoscopy 2007; 39: 793-801

[10] Colton JB, Curran CC. Quality indicators, including complications, of ERCP in a community setting: a prospective study. Gastrointest Endosc 2009; 70: $457-467$

[11] Cotton PB, Lehman G, Vennes J et al. Endoscopic sphincterotomy complications and their management: an attempt at consensus. Gastrointest Endosc 1991; 37: 383-393
[12] Andriulli A, Loperfido S, Napolitano G et al. Incidence rates of postERCP complications: a systematic survey of prospective studies. Am J Gastroenterol 2007; 102: $1781-1788$

[13] Cotton PB, Garrow DA, Gallagher J et al. Risk factors for complications after ERCP: a multivariable analysis of 11,497 procedures over 12 years. Gastrointest Endosc 2009; 70: $80-88$

[14] Barthet M, Lesavre N, Desjeux A et al. Complications of endoscopic sphincterotomy: results from a single tertiary referral center. Endoscopy 2002; 34: 991 - 997

[15] Williams EJ, Green J, Beckingham I et al. Guidelines on the management of common bile duct stones (CBDS). Gut 2008; 57: 1004- 1021

[16] Maple JT, Ikenberry SO, Anderson MA et al. The role of endoscopy in the management of choledocholithiasis. Gastrointest Endosc 2011; 74: $731-744$

[17] Tazuma S, Unno M, Igarashi Y et al. Evidence-based clinical practice guidelines for cholelithiasis 2016. J Gastroenterol 2017; 52: 276-300

[18] Johnson AG, Hosking SW. Appraisal of the management of bile duct stones. Br J Surg 1987; 74: 555 - 560

[19] United Nations, Department of Economic and Social Affairs. World Population Prospects: The 2015 Revision, Key Findings and Advance Tables. https://esa.un.org/unpd/wpp/Publications/ Updated 29 July 2015

[20] Jorgensen J, Kubiliun N, Law JK. Endoscopic retrograde cholangiography (ERCP): core curriculum. Gastrointest Endosc 2016; 83: 279-289

[21] Wang P, Li ZS, Liu F et al. Risk factors for ERCP-related complications: a prospective multicenter study. Am J Gastroenterol 2009; 104: 31 - 40

[22] Kiriyama S, Takada T, Strasberg SM et al. TG13 guidelines for diagnosis and severity grading of acute cholangitis. J Hepatobiliary Pancreat Sci 2013; 20: 24-34

[23] Pezzilli R, Romboli E, Campana D et al. Mechanisms involved in the onset of post-ERCP pancreatitis. JOP 2002; 3: 162 - 168

[24] Kuo CM, Chiu YC, Liang CM et al. Limited precut sphincterotomy combined with endoscopic papillary balloon dilation for common bile duct stone removal in patients with difficult biliary cannulation. BMC Gastroenterol 2016; 16: 70

[25] Collins C, Maguire D, Ireland A et al. A prospective study of common bile duct calculi in patients undergoing laparoscopic cholecystectomy: natural history of choledocholithiasis revisited. Ann Surg 2004; 239: $28-33$

[26] Neuhaus H, Feussner $\mathrm{H}$, Ungeheuer A et al. Prospective evaluation of the use of endoscopic retrograde cholangiography prior to laparoscopic cholecystectomy. Endoscopy 1992; 24: 745 - 749

[27] Welbourn CR, Mehta D, Armstrong CP et al. Selective preoperative endoscopic retrograde cholangiography with sphincterotomy avoids bile duct exploration during laparoscopic cholecystectomy. Gut 1995; 37: $576-579$

[28] Gupta N. Role of laparoscopic common bile duct exploration in the management of choledocholithiasis. World J Gastrointest Surg 2016; 8: $376-381$

[29] Baucom RB, Feurer ID, Shelton JS et al. Surgeons, ERCP, and laparoscopic common bile duct exploration: do we need a standard approach for common bile duct stones? Surg Endosc 2016; 30: 414 423

[30] Nishikawa T, Tsuyuguchi T, Sakai Y et al. Old age is associated with increased severity of complications in endoscopic biliary stone removal. Dig Endosc 2014; 26: 569-576 